\title{
BREEDER-HELPER-INTERACTIONS IN THE PIED KINGFISHER REFLECT THE COSTS AND BENEFITS OF COOPERATIVE BREEDING
}

\author{
by \\ HEINZ-ULRICH REYER ${ }^{1}$ ) \\ (Max-Planck-Institut für Verhaltensphysiologie, D-8131 Seewiesen, West Germany)
}

\section{Introduction}

Cooperative breeding, in which helpers assist parents in raising offspring, is increasingly viewed as a result of ecological constraints that limit the helpers' possibility of independent reproduction (Brown, 1974, 1982; Gaston, 1978; Woolfenden \& Fitzpatrick, 1978; Koenig \& Pitelka, 1981; Emlen, 1982a; Emlen \& Vehrencamp, 1983). Proximate reasons for this limitation include the shortage of breeding territories and sexual partners, as well as prohibitive costs of early dispersal and reproduction. These conditions favour the association of grown offspring with established breeders, usually their parents. From this first step cooperative breeding will develop if the inclusive fitness of non-breeders and breeders is increased by giving and receiving help, respectively (for summaries see Brown, 1978, 1985; EMLEN, 1978, 1984).

According to this series of hypotheses, helping is superior to nonhelping, but inferior to independent reproduction. Consequently, competition between helpers and established breeders is to be expected. There is plenty of evidence for the existence of such competition: Direct aggression between group members, regular copulations by male helpers with breeding females, mate-guarding by male breeders, parasitic egg-

$\left.{ }^{1}\right)$ This study is part of a long term project on the behavioral ecology of African kingfishers, sponsored by the Max-Planck-Gesellschaft. I am grateful to W. WICKLER for his continuing interest in and support of the project and to the many people who helped in collecting field data, in particular to Dieter Schmid, who also drew the Figures. The manuscript was written while I was a Visiting Associate Professor at Cornell University, Ithaca. I am grateful to the Section of Neurobiology and Behavior for its hospitality, and especially to R. Chariff, S. T. Emlen, P. W. Sherman, P. W. Watson and P. H. WREGE who made valuable comments on earlier versions of the manuscript. 
laying by females, egg tossing and infanticide have been reported for several species of cooperatively breeding mammals, birds and fishes (for overviews and references see Brown, 1978; EMLEN, 1982b, 1984; TABORSKY, 1985). The precise extent of such competition should depend on how much the costs and benefits of breeders and helpers diverge. This, in turn, should be influenced by a wide variety of ecological and demographic features. Among the most important are: (a) habitat saturation, predator pressure, and food availability, all affecting the parents' need for helpers, as well as the helpers' gains from living in a good territory, getting experience or establishing beneficial bonds for their own future reproduction; (b) age and sex of helpers in relation to age and sex of breeders, as well as period of the reproductive cycle, all affecting the amount of competition and fitness reduction a breeder faces; (c) operational sex ratio in the population, affecting the surplus birds' chances of independent reproduction; (d) relatedness between breeders and helpers, affecting the helpers' kin benefits from raising young, as well as the degree to which the breeders' tolerance toward helpers can be viewed as extended brood care.

This list of factors, which is by no means exhaustive, is mainly based on models of cooperation and conflict (Brown, 1974, 1982, 1985; KoENIG \& Pitelka, 1981; Emlen, 1982a, b; Emlen \& Vehrencamp, 1983). Some studies and observations on one or the other of these factors confirm the theoretical predictions. These include (a) higher within-group competion in areas where helpers have low chances of survival and breeding as opposed to areas where these chances are high (e.g. discussion in Joste $e t$ al., 1982); (b) a preponderance of mate-guarding during times of egg-laying, particularly against conspecifics of the same sex (e.g. Dow, 1977; Mumme et al., 1982; EmLen \& Wrege, in press); and (c) higher levels of aggression between individuals that are less related or less familiar with each other than between close relatives and/or close associates (e.g. Woolfenden \& Fitzpatrick, 1977; Dow, 1979; Hert, 1985). There exists, however, only one study which systematically analyses the effect of more than one of the above proximate factors on competition. In laboratory experiments, TABORSKY $(1984,1985)$ quantified breederhelper interactions in the cichlid fish Lamprologus brichardi in relation to sex, age, stage of the reproductive cycle and competition for territories and shelter. The complete lack of comparable field studies is not surprising if one considers the limited possibility of conducting relevant experiments in the field, the poor visibility of several cooperative breeders (making it tedious to quantify interactions), and the difficulty of for- 
mulating precise expectations where numerous combinations of confounding variables are possible.

For various reasons, these difficulties are less pronounced in pied kingfishers (Ceryle rudis) than in most other cooperative breeders: (a) pied kingfishers live in open habitat, thus allowing relatively easy observation of behavioral interactions; (b) they are colonial instead of territorial, so that the costs and benefits of helping are unbiased by the costs and benefits of territoriality (cf. Brown, 1978); (c) only males are helping; (d) the existence of closely related and completely unrelated helpers, rather than of more or less related helpers, allows separation of individual from kin benefits; (e) the effect of help is pronounced for both helpers and breeders, and can be related to ecological conditions; and ( $f$ ) the birds respond to experimental changes of field conditions with changes in their social structure.

In this study I used these advantages to quantify in the field, how the sex of the breeder, the helper's relatedness to the breeder and his young, and the period of the reproductive cycle affect breeder-helper interactions and the amount of help which helpers provide.

\section{The bird and its breeding system}

Pied kingfishers are common fish-eating birds that occur along rivers and fresh-water lakes in Africa. They often breed in colonies where they have helpers at the nest. Between 1976 and 1984, I compared the cooperative breeding systems in two marked populations in Kenya, one at Lake Victoria, the other at L. Naivasha. Without exception, all helpers in both colonies were males $(n=121)$. Seven percent consisted of mated males who did not breed in the year they helped, the remaining $93 \%$ were not paired. This high percentage of unmated males arises from a highly skewed adult sex ratio (1.4-2.5:1), which has been found in all populations of pied kingfishers studied so far (Douthwaite, 1973; SugG, 1974; REYER, 1980, and unpubl. data).

Among the male helpers there are two different types: primary and secondary (REYER, 1980). Primary helpers are one or two year old offspring of the breeding pair. They remain with and are tolerated by their parent(s) throughout the year, thus forming a permanent cooperative group. After one or two years as primary helpers the birds usually become breeders or secondary helpers. Secondary helpers are typically two or three years old and thereafter become breeders. They are not related to the breeders they join as helpers and are not regularly observed in the group until a few days after the young have hatched. Therefore, in this paper, the term "secondary helpers" is used only after a bird has become a group member; prior to joining I speak of "potential secondary helpers" or "extra-group-males". Potential secondary helpers try to feed various females from the very beginning of the breeding season (Fig. 1 in REYER, 1984) and apparently remain where they are tolerated first. Once they have associated with a group they restrict their activities to that particular group. Primary and secondary helpers feed the young and guard the nest against predators such as monitor lizards (Varanus niloticus), cobras (Naja spec.), and the ichneumon (Herpestes spec.). In addition, primary helpers engage in some activities that are not open to secondary helpers because of their later association with breeders. Among these are chasing away competitors for nest-sites and the regular feeding 
of male and female breeders prior to egg-laying. Primary helpers do not, however, participate in tunneling, incubating and brooding, nor do they copulate (REYER, 1980, 1984).

At L. Victoria, out of 51 completely marked breeding groups, $19(=37 \%)$ had no helpers when feeding nestlings, $11(=22 \%)$ had one primary helper, $11(=22 \%)$ had one to three secondary helpers, and $10(=20 \%)$ had one primary plus one to three secondary helpers. If groups are included in which the composition is not known completely, and helpers are considered that were not marked but could be recognized by plumage and/or behavioral peculiarities, the number of primary helpers totals $47(=49.5 \%$ of all helpers $)$, that of secondary helpers $48(=50.5 \%)$. Thus, the two types seem to be about equally frequent at L. Victoria. At L. Naivasha, where fewer years of observations are available, the numbers of primary and secondary helpers feeding nestlings were $21(=80.8 \%)$ and 5 $(=19.2 \%)$ respectively, i.e. the proportion of secondary helpers was significantly lower $\left(\chi^{2}=8.122, p=0.004\right)$. Although many more potential secondary helpers were present at L. Naivasha, these were not accepted by breeders and their primary helpers (ReYER, 1980; REYER \& WESTERTERP, 1985). This contrasts with L. Victoria where every potential helper finally was admitted into a group.

The different treatment at the two lakes plus the observation that at L. Victoria primary and secondary helpers are accepted at different stages of the breeding season, suggest that the two helper types impose differential costs and benefits on breeders. The importance of environmental conditions for this cost/benefit ratio has been examined elsewhere (REYER \& WESTERTERP, 1985). In this paper I first analyse the behavioral interactions between, and food contributions of mated males, mated females, primary helpers and secondary helpers from L. Victoria. I then relate the results to the costs and benefits of giving and receiving help with respect to the type of the helper, the sex of the recipient and the stage of the breeding season.

\section{Methods}

Data were collected during 6 breeding seasons (April-August, 1978-1983) on a marked population of ca. 65 pied kingfishers, living in a colony at Lake Victoria. Three types of behavioral interactions were analysed:

a) Aggressive and non-aggressive interactions: When two birds met I recorded their identities from colour rings and/or artificially dyed plumage parts. I further noted whether or not at least one of the birds carried a fish and whether the meeting was followed by an aggressive interaction (pecking, beak-twisting, chasing) or by a non-aggressive one (greeting, sitting together). A detailed description of these behavior patterns is provided by Dunn (1985) and Reyer \& Dunn (1985).

Due to difficulties in reliably recognizing individuals (especially when in the air) and due to the necessity of other observations, data were gathered whenever conditions allowed. Consequently, sample sizes from individual birds are small (usually 2-3, range 1-6) and do not allow separate statistical treatment of different cooperative groups. Instead, records for particular combinations (e.g. male-primary helper, female-secondary helper) were pooled over all birds belonging to that combination. In a first analysis, data were broken down into three periods, each consisting of two years $(1978 / 79, \mathrm{n}=123$ observations; $1980 / 81, \mathrm{n}=79 ; 1982 / 83, \mathrm{n}=105)$. When tested for inter-period variations (Fisher exact probability test), no significant differences were found for any of the various combinations, so data from all six years were combined. Observations before and after hatching were treated separately (Table 1).

b) Begging and feeding of females: 3-10 days after their young had hatched 7 females were observed for 5.5 to 24 hours to determine how often they begged to potential secondary helpers (females 1-7), and how often to their mates (females 1-6) or to primary helpers (female 7). I also recorded how often the respective males responded to the begging by feeding the females (Table 2). 
c) Type and size of food: Feeding was also monitored with respect to type and size of fish taken to females by secondary helpers and to nestlings by male breeders, female breeders, primary helpers and secondary helpers. Fish types were separated into Engraulicypris argenteus (E; Cyprinidae) and cichlid fishes (C; Cichlidae). The proportion of these prey types is expressed as the ratio $\mathrm{E} / \mathrm{C}$. As such ratios can be biased when sample sizes are small, individuals with low daily feeding frequencies were pooled until the total number of fish/day was 10 or more. To record size of prey items, birds bringing fish were photographed, fish lengths later measured in relation to beak lengths and then converted into kcal (for calculations see formula 1 and Table 2 in REYER, 1984). Average energy content/fish was calculated for each feeding adult separately and then averaged within two categories of birds: a) secondary helpers, b) male breeders, female breeders and primary helpers combined (Fig. 1). Pooling of the latter three bird categories is justified as they bring prey of equal size (Fig. 2c in REYER, 1984). A secondary helper's individual feeding contribution to nestlings was further expressed as a proportion of what the breeding male of the same cooperative unit fed during the same day. The resulting ratios were then compared between groups with one secondary helper and groups with two or three secondary helpers (Fig. 2).

In contrast to observations on aggressive and non-aggressive interactions, which were taken irregularly, observations on begging and feeding frequencies and on type and size of food were particularly focussed upon. As far as nestlings are concerned, this resulted in a complete feeding record, as previous observations in the nest hole had shown that pied kingfishers bring fish singly and do not regurgitate food. Observed frequencies of food transfer between adults, however, are likely to be underestimates, because feeding also occurred when the focal animals were out of sight.

As most data were not normally distributed, non-parametric statistical tests and medians plus interquartile ranges are used throughout this paper.

\section{Results}

Behavioral interactions before hatching.

Throughout the reproductive season, female breeders are not very selective as to who feeds them. They will beg and accept fish from any advancing male. After having been fed, they tolerate extra-group males as readily besides them as they tolerate their mates and primary helpers (Table 1; comparisons 1a, b). However, extra-group males approaching without a fish are more often attacked by females than either mates or primary helpers without fish (Table 1; comp. 2a, b). Thus, extra-group males seem to ease access to females by feeding them (Table 1; comp. 3), whereas interactions within an established group are independent of whether or not the approaching bird carries a fish (Table 1; comp. 4a-i).

Although the figures in rows 1,3 and 5 of Table 1 give the impression that potential secondary helpers feed females as frequently as do mates and primary helpers, this is not the case. The result is biased because observers paid more attention to the unusual female-potential secondary helper interaction than to the regular female-male and female-primary helper interactions. In reality, contact between females and extra-group males is usually prevented by the females' mates and occasionally by 
TABLE 1. Frequencies of aggressive and non-aggressive interactions between mat males, mated females, primary helpers $\left(1^{\circ}\right)$ and secondary helpers $\left(2^{\circ}\right)$

\begin{tabular}{|c|c|c|c|c|c|c|}
\hline \multirow[t]{2}{*}{ Period } & \multirow[t]{2}{*}{ Combination } & \multicolumn{2}{|c|}{ With fish } & \multicolumn{2}{|c|}{ Without fish } & \multirow[t]{2}{*}{ Row } \\
\hline & & $\begin{array}{c}\text { aggression } \\
1\end{array}$ & $\begin{array}{c}\text { no aggression } \\
2\end{array}$ & $\begin{array}{c}\text { aggression } \\
3\end{array}$ & $\begin{array}{c}\text { no aggression } \\
4\end{array}$ & \\
\hline \multirow{6}{*}{$\begin{array}{l}\text { Before } \\
\text { hatching }\end{array}$} & male-female & 2 & 34 & 5 & 46 & 1 \\
\hline & male- $1^{\circ}$ helper & 1 & 15 & 4 & 42 & 2 \\
\hline & female- $1^{\circ}$ helper & 2 & 25 & 0 & 27 & 3 \\
\hline & male- $2^{\circ}$ helper & 15 & 7 & 24 & 7 & 4 \\
\hline & female- $2^{\circ}$ helper & 0 & 22 & 8 & 17 & 5 \\
\hline & $1^{\circ}$ helper- $2^{\circ}$ helper & 2 & 0 & 8 & 1 & 6 \\
\hline \multirow{3}{*}{$\begin{array}{l}\text { After } \\
\text { hatching }\end{array}$} & male- $2^{\circ}$ helper & 2 & 9 & 12 & 4 & 7 \\
\hline & female- $2^{\circ}$ helper & 0 & 24 & 1 & 4 & 8 \\
\hline & $1^{\circ}$ helper- $2^{\circ}$ helper & 1 & 3 & 0 & 1 & 9 \\
\hline
\end{tabular}

Encounters are divided into those with fish (columns 1 and 2) and those without fish (columns 3 and as well as into those before (rows 1-6) and after hatching of the young (rows 7-9). Frequencies were st jected to the seven comparisons (comp.) mentioned in the text. Below, these comparisons are designal by the respective cells in the table, with a figure before the slash indicating the row and a figure behine the column. E.g. $5 / 1 ; 5 / 2$ vs $1 / 1 ; 1 / 2$ means that the frequencies from row 5 , columns 1 and 2 were co pared with those in row 1, columns 1 and 2 . Comparisons were statistically tested using Fisher ex probability test. Given are two-tailed probabilities (in brackets). Significant results are marked with

comp. 1: $5 / 1 ; 5 / 2$ os $1 / 1 ; 1 / 2(\mathrm{a}: \mathrm{p}=0.762)$ and $v s 3 / 1 ; 3 / 2(\mathrm{~b}: \mathrm{p}=0.597)$

*comp. 2 : $5 / 3 ; 5 / 4$ os $1 / 3 ; 1 / 4(\mathrm{a}: \mathrm{p}=0.041)$ and os $3 / 3 ; 3 / 4(\mathrm{~b}: \mathrm{p}=0.003)$

*comp. 3: $5 / 1 ; 5 / 2$ us $5 / 3 ; 5 / 4(\mathrm{p}=0.007)$

comp. 4 : $1 / 1 ; 1 / 2$ is $2 / 1 ; 2 / 2$ (a) and is $3 / 1 ; 3 / 2$ (b)

$2 / 1 ; 2 / 2$ os $3 / 1 ; 3 / 2$ (c)

$1 / 3 ; 1 / 4$ os $2 / 3 ; 2 / 4$ (d) and os $3 / 3 ; 3 / 4$ (e)

$2 / 3 ; 2 / 4$ os $3 / 3 ; 3 / 4$ (f)

$1 / 1 ; 1 / 2$ os $1 / 3 ; 1 / 4(\mathrm{~g})$

(all $\mathrm{p} \geq 0.223$ )

$2 / 1 ; 2 / 2$ os $2 / 3 ; 2 / 4(\mathrm{~h})$

$3 / 1 ; 3 / 2$ os $3 / 3 ; 3 / 4(\mathrm{i})$;

comp. $5: 4 / 1 ; 4 / 2$ os $4 / 3 ; 4 / 4(\mathrm{a}: \mathrm{p}=0.659)$ and $6 / 1 ; 6 / 2$ vs $6 / 3 ; 6 / 4$ (b: ns)

*comp. 6: $(7 / 1+9 / 1) ;(7 / 2+9 / 2)$ os $(7 / 3+9 / 3) ;(7 / 4+9 / 4)(\mathrm{p}=0.011)$

comp. $7: 8 / 1 ; 8 / 2$ os $8 / 3 ; 8 / 4(\mathrm{p}=0.345)$.

their sons (= primary helpers) as well. These will intercept approaching males in the air and drive them away, frequently after snatching their fish. In contrast to interactions between females and potential secondary helpers, the way group-males treat potential secondary helpers is independent of whether a fish is brought or not: attacks prevail in any case (Table 1; comp. 5a,b).

If a group-male obtains a fish from the rejected extra-group male, the prey is either swallowed or, more often, taken to the female. This behavior, which continues through the incubation period, assures that a 
CABLE 2. Average frequencies/h with which seven females (column 1) begged food rom seven individually marked group males (columns 2-4) and seven marked extragroup males (columns 5-7) when these males approached with fish

\begin{tabular}{|c|c|c|c|c|c|c|c|c|}
\hline \multirow{2}{*}{$\begin{array}{l}\text { emale } \\
\text { o. }\end{array}$} & \multicolumn{3}{|c|}{ Group males } & \multicolumn{3}{|c|}{ Extra-group males } & \multicolumn{2}{|c|}{ Observation } \\
\hline & $\underset{2}{\text { begging }}$ & $\begin{array}{c}\text { fed } \\
3\end{array}$ & $\begin{array}{c}\text { not fed } \\
4\end{array}$ & $\underset{5}{\text { begging }}$ & $\begin{array}{c}\text { fed } \\
6\end{array}$ & $\begin{array}{c}\text { not fed } \\
7\end{array}$ & $\begin{array}{l}\mathrm{h} \\
8\end{array}$ & $\begin{array}{c}\text { year } \\
9\end{array}$ \\
\hline & 0.42 & 0.17 & 0.25 & 0.58 & 0.58 & 0 & 12.0 & 1978 \\
\hline & 0.35 & 0 & 0.35 & 0.59 & 0.59 & 0 & 8.5 & 1978 \\
\hline & 0.36 & 0 & 0.36 & 0.36 & 0.36 & 0 & 5.5 & 1978 \\
\hline & 1.00 & 0 & 1.00 & 1.20 & 1.20 & 0 & 5.0 & 1979 \\
\hline & 0.50 & 0.08 & 0.42 & 0.63 & 0.63 & 0 & 24.0 & 1982 \\
\hline & 0.33 & 0.08 & 0.25 & 0.58 & 0.58 & 0 & 12.0 & 1982 \\
\hline & 0.46 & 0.08 & 0.38 & 0.54 & 0.54 & 0 & 24.0 & 1982 \\
\hline & 0.42 & 0.08 & 0.36 & 0.58 & 0.58 & 0 & & \\
\hline & 0.35 & 0.00 & 0.25 & 0.54 & 0.54 & 0 & & \\
\hline$q$ & 0.50 & 0.08 & 0.42 & 0.63 & 0.63 & 0 & & \\
\hline
\end{tabular}

Values are based on the number of observation hours (h) given in column 8 . Columns 2 and 5 give the otal number of encounters with begging. These are broken down into cases in which the begging emales were fed (columns 3 and 6 ) and those in which they were not (columns 4 and 7 ). As values did ot differ very much between females from different years (column 9), they were averaged over all seven ndividuals (lower part of the Table). Given are medians ( $\mathrm{x}$ ), lower quartiles (lq) and upper quartiles uq). For statistics see text.

female is fed predominantly by her mate and her primary helper(s), at least until the young have hatched. The guarding may also prevent potential secondary helpers from kleptogamy. Their infrequent and brief contact with females may usually not suffice for initiating and completing copulations. All of the 53 observed copulations between identified individuals were between the respective mates.

Behavioral interactions after hatching.

Once the young have hatched, mate and primary helper decrease their food transfers to the female sharply within one or two days although she continues to beg for at least another 7-10 days. This is the time when extra-group males start to feed her regularly. Seven females who were observed while their young were between 3 and 10 days old, received an average of $0.08 \mathrm{fish} / \mathrm{h}$ from their mates or primary helpers as opposed to $0.58 \mathrm{fish} / \mathrm{h}$ from potential secondary helpers $(\mathrm{p}=0.02$, Wilcoxon-test, two-tailed, applied to columns 3 and 6 of Table 2). The actual figures are 
probably higher as these values include only cases in which feeding individuals were identified. Often a female flew toward an unidentified approaching bird or even disappeared briefly to return with a fish. This, however, should not affect the ratio between group-male and extragroup-male feeding. As only banded birds were considered, mates and primary helpers were as likely to be missed as potential secondary helpers, unless one assumes that one male category is regularly approached at greater distances from the observer than the other. This did not seem to be the case.

The main reasons for the above difference in feeding frequencies are:

1. Females beg from their mates and primary helpers less often than from potential secondary helpers $(p=0.05$, Wilcoxon-test, two-tailed, applied to columns 2 and 5 of Table 2), although the former arrive near the female more often.

2. When approached and begged at, mates and primary helpers rarely feed the female whereas potential secondary helpers always do. This difference is significant for 5 out of the 7 combinations in Table 2 (Fishertest, two-tailed, applied to cells 3 and 4 vs 6 and 7 ) and for the combined result from all seven females $\left(\mathrm{p}<0.001, \chi^{2}=77.45, \mathrm{df}=14\right.$; Sokal \& RohlF, 1969, p. 623).

During the first two or three days after hatching a potential secondary helper seems to succeed in feeding a female only because she remains unguarded for considerable periods. She usually stays in the colony, occasionally brooding the young, while her mate and the primary helper spend an increasing amount of time at the lake, catching fish for the young. Whenever the group males meet a potential secondary helper close to the female, they will attack him as they did before egg-laying. If the potential helper holds a fish he will offer it to the attacking bird. In contrast to pre-hatching periods, now the transfer has an effect on the males as well: passing food significantly reduces the probability of the potential secondary helper being attacked (Table 1; comp. 6). Sometimes the fish is transferred back and forth up to 4 or 5 times between the same two individuals. The receiving bird takes the fish from the donor, head first, then turns the prey round by $180^{\circ}$, offers it backs so that the former donor obtains it head first, etc. The fish may even be passed to a further member of the cooperative group, e.g. from the primary helper to the male or from the male to the female, before it is finally taken to the nestlings by someone.

During the first 3-4 days after hatching, when group males still frequently attack potential secondary helpers, particularly those without 
fish, females tolerate extra-group males already, independent of whether or not they bring a fish (Table 1; comp. 7). Thus, females accept secondary helpers as regular group members sooner than do males. During the following days, however, fish transfers from secondary helpers to male mates and primary helpers become less and less aggressive until even secondary helpers without fish are tolerated. This happens usually 4-7 days after the young have hatched.

a) $\mathrm{Kcal} / \mathrm{fish}$

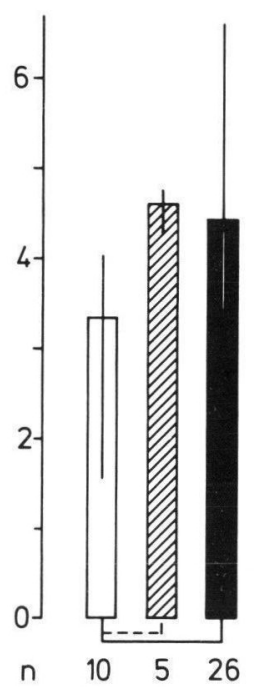

b) ratio $E / C$

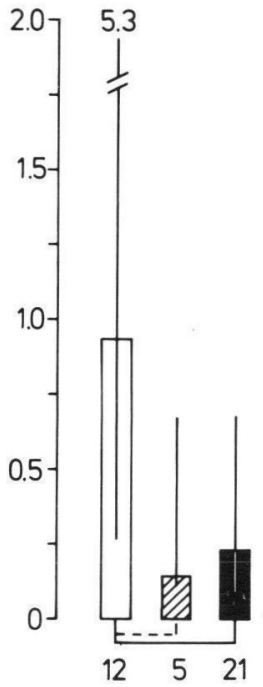

Fig. 1. a) Fish size (Kcal) and b) ratio of Engraulicypris argenteus (Cyprinidae) to cichlid fishes (Cichlidae) fed by secondary helpers to nestlings (white) and their mothers (hatches). Size and ratio fed by parents and primary helpers (pooled) are also given (black). Medians are shown with interquartile ranges. Sample sizes $(n)$ at the bottom of the Figure refer to number of observed individuals. Bars are connected by horizontal lines if the difference between them is significant at $\mathrm{p} \leq 0.01(-)$ ) or at $\mathrm{p} \leq 0.05(---)$ (MannWhitney U-test, one tailed).

Type and size of prey.

About 7-10 days after hatching, when the growing young require less brooding but more and more food, the females decrease their begging and increasingly catch fish themselves. At this stage the now accepted secondary helpers shift from feeding the nestlings via other group members to feeding them directly, although they continue to feed the female if she begs at them. The shift is accompanied by a change in size 
and type of fish. To nestlings the secondary helpers take significantly smaller fish (Fig. 1a) and a lower proportion of cichlid fishes (Fig. 1b) than to the female breeders. The shift to smaller fish is not dictated by the nestlings' smaller size because parents and primary helpers contribute significantly larger fish and more cichlids at this time (black bars in Figs $1 \mathrm{a}, \mathrm{b})$. Hand-rearing of young pied kingfishers also showed that one week old nestlings can swallow cichlids as large as $9.2 \mathrm{kcal}(=68 \mathrm{~mm}$ standard length).

By bringing smaller fish and a higher E/C-ratio to nestlings, secondary helpers save considerable time and energy, which in turn leads to an increase in survival rate (see Discussion of Result 6). The fact that they apparently do not try to minimize costs when feeding females suggests that the transfer of big nutritious cichlids may serve as a signal, that somehow affects the helpers' fitness. Further support for this hypothesis comes from a comparison of groups with different numbers of secondary helpers and thus probably different degrees of male-male competition (Fig. 2). In groups with two or three secondary helpers, each helper's feeding contribution to nestlings $(\mathrm{kcal} / \mathrm{d})$ on average amounted to $71 \%$ of what male breeders fed, as opposed to $19 \%$ in groups with one secondary helper (Fig. 2a; $\mathrm{p}=0.083$, Mann-Whitney U-test, one-tailed). The difference seems to result both from differences in size of fish (55\% vs $32 \%$; Fig. 2b) and number of fish $(71 \%$ vs $60 \%$; Fig. 2c); but size differences are only marginally significant $(\mathrm{p}=0.083)$, and differences in numbers are not significant. As to the types of fishes, secondary helpers in bigger groups seemed to bring a higher proportion of the more costly cichlid fishes to nestlings than secondary helpers in smaller groups did (Fig. 2d). This difference in the $\mathrm{E} / \mathrm{C}$-ratio, however, was not significant either, which is not surprising. Even when birds were lumped to get sample sizes $\geq 10$ (see Methods), variation was extremely high (cf. Fig. 1b). Using data from single birds, as had to be done for this comparison between groups with 1 and $\geq 2$ secondary helpers, increased variation even further.

Although none of the differences in the above comparisons is convincing in itself, results from three measurements (size, number and type of fish) point in the same direction: higher feeding effort of secondary helpers in bigger groups. Moreover, the above tests are conservative ones, done under the null hypothesis of no differences between groups. With participation of more helpers, however, one should expect a lower individual feeding effort in bigger groups, provided the food requirements of the young did not differ between small and big groups. Since the extent of such lowering could not be predicted quantitatively, 


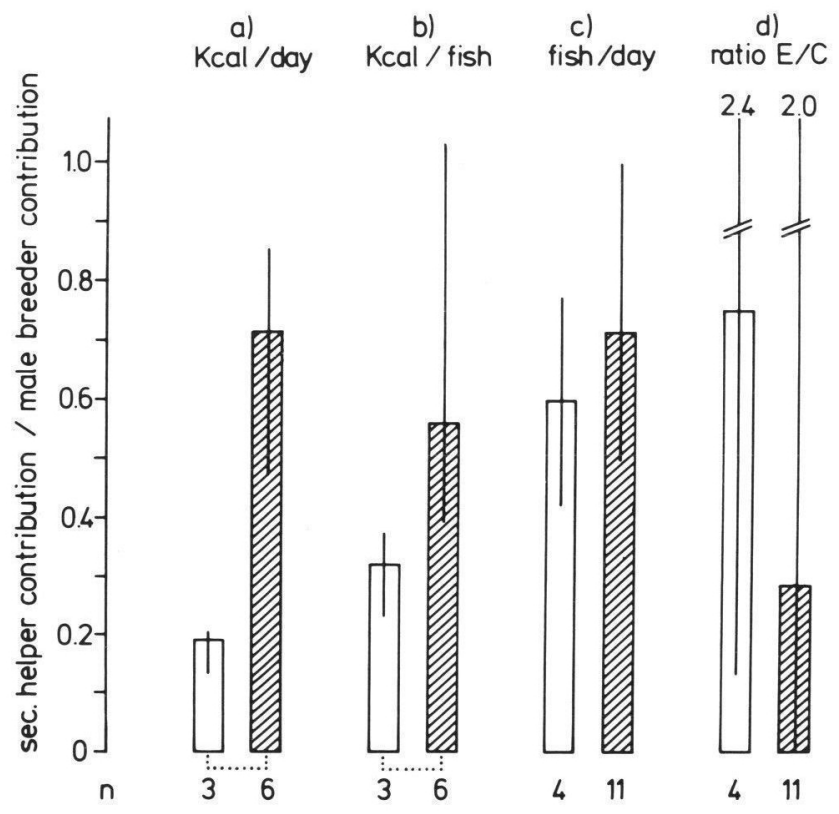

Fig. 2. Feeding of nestlings by individual secondary helpers as a proportion of what male breeders of the same cooperative unit fed. Shown are medians and interquartile ranges for (a) total daily energy (kcal/d), (b) average fish size ( $\mathrm{kcal} / \mathrm{fish}$ ), (c) number of fish/d, and (d) ratio between Engraulicypris argenteus (E) and chichlids (C). Sample sizes (n) below the graph refer to numbers of individually recorded birds from groups with one secondary helper (white bars) and groups with $\geq 2$ secondary helpers (hatched bars). Bars are connected by dotted lines if the difference between them is marginally significant $(p<0.10$; Mann-Whitney U-test, one-tailed).

equal individual contributions had to be assumed for the test. Food requirements of nestlings were probably equal as the two categories did not differ in average clutch size $(4.25 \pm 0.96$ in groups with 1 secondary helper $v$ s $4.20 \pm 0.45$ in groups with $\geq 2$ helpers) or in the average age of the nestlings $(14.3 \pm 3.8$ vs $13.4 \pm 1.9$ days $)$. Thus, the food requirements of the nestlings do not explain the higher individual feeding contribution in bigger groups. Possible signal functions of feeding and their relation to male-male competition over females will be addressed in the Discussion of Results 4 and 6. Further evidence for the existence of such competition is presented in the following section.

Male-male competition after the breeding season.

Even after the young have fledged, the male-male conflict continues. At the end of each breeding season, intense and prolonged fights do occur 
TABLE 3. Frequencies of pairing between former primary helpers (a) or former secondary helpers (b) and the females they had helped the previous year, in relation to presence and absence of these females' former mates (columns 1 and 2)

\begin{tabular}{|c|c|c|c|c|c|c|c|}
\hline \multirow{2}{*}{$\begin{array}{l}\text { Former } \\
\text { male }\end{array}$} & \multicolumn{4}{|c|}{ Helper mated } & \multicolumn{2}{|c|}{ Total of } & \multirow{2}{*}{$\begin{array}{c}\text { Total of } \\
\text { marked } \\
\text { helpers } \\
7\end{array}$} \\
\hline & $\begin{array}{c}\text { To helped } \\
\text { female } \\
1\end{array}$ & $\begin{array}{l}\text { To other } \\
\text { female } \\
2\end{array}$ & $\begin{array}{c}\text { Yes } \\
3\end{array}$ & $\begin{array}{l}\text { No } \\
4\end{array}$ & $\begin{array}{l}\text { Mated } \\
\text { helpers } \\
5\end{array}$ & $\begin{array}{l}\text { Surviving } \\
\text { helpers } \\
6\end{array}$ & \\
\hline $\begin{array}{l}\text { Present } \\
\text { Absent }\end{array}$ & $\begin{array}{l}0 \\
2\end{array}$ & $\begin{array}{l}3 \\
4\end{array}$ & 0 & 6 & 9 & 15 & 28 \\
\hline $\begin{array}{l}\text { Present } \\
\text { Absent }\end{array}$ & $\begin{array}{l}3 \\
7\end{array}$ & $\begin{array}{l}5 \\
0\end{array}$ & 6 & 2 & 21 & 23 & 31 \\
\hline \multicolumn{3}{|c|}{$\begin{array}{l}\text { Present } \\
\quad \text { Helped female }\end{array}$} & & & & & \\
\hline
\end{tabular}

Also given are figures on how often former helpers were paired or not in the absence of the helped female (columns 3 and 4 ), how often they were paired in total (column $5=$ columns $1+2+3$ ), and how many of the individually marked helpers (column 7) survived into the next year $($ column $6=$ columns $4+5)$. For statistics see text.

between male breeders and their former secondary helpers, but have never been observed between breeders and primary helpers. Such fights can cause injuries (see also SugG, 1974) and/or result in female take-over. Again, such take-over is confined to secondary helpers. The following calculation will demonstrate this point, by using previously published data (REYER, 1984) which have been updated where sample sizes have increased (Table 3).

Competition between a male breeder and his helper over the female as a future mate will occur if all three birds of the cooperative group survive to the next breeding attempt, which is usually the next year. Considering only such cases, 3 out of 8 secondary helpers were mated to the female they had helped the year before $(=37.5 \%)$, as opposed to none out of 3 primary helpers ( $=0 \%$; first rows of columns 1 and 2 in Table $3 a, b)$. Although far from being significant $(\mathrm{p}=0.68$, Fisher test, two-tailed), the higher competition from secondary helpers is to be expected from two other sets of data, both based on large sampler sizes:

a) Secondary helpers tend to have a higher return rate than primary helpers $\left(0.74\right.$ os $0.54 ; \chi^{2}=2.729, \mathrm{df}=1, \mathrm{p}<0.10$; Table 3 , columns 6 and 7). This difference reflects a difference in survival rather than in dispersal (REYER, 1984). The likely cause of lower survivorship among primary 
helpers is their higher feeding contribution to the nestlings which carries them to the limits of their energetic capacity (REYER, 1984, Fig. 2; ReYer \& WeSTERTERP, 1985).

b) Among the surviving helpers, there is a difference in the tendency to mate with the female they have helped the year before. Secondary helpers mate with widowed females significantly more often than with those whose previous males are still alive $(p=0.037$, Fisher test, twotailed; Table 3b, columns 1 and 2). This indicates, that the presence of the previous male is the main obstacle for mating with the helped female. For primary helpers, on the other hand, presence or absence of the previous mate makes no difference $(\mathrm{p}=0.833$, Fisher test, two-tailed; Table $3 \mathrm{a}$, columns 1 and 2). They mate with the females, who are usually their mothers, significantly less often than do secondary helpers, even when the former males are no longer there $(p=0.042$, Fisher test, twotailed; cp. second rows in columns 1 and 2 of Tables 3a, b). Each of the two matings between a primary helper and the female he had helped the previous year, involved a stepmother.

The probability ( $p$ ) that a male breeder will lose his female to his former helper is:

$$
\mathrm{p}=1_{\mathrm{O}^{\prime}} \cdot 1_{\odot} \cdot 1_{\mathrm{H}} \cdot \mathrm{q}_{\mathrm{H}}
$$

Here, $l_{\sigma^{*}}, l_{\rho}$ and $l_{H}$ are the survival rates of male breeders, female breeders and helpers, respectively, and $\mathrm{qH}_{\mathrm{H}}$ is the helper's probability of female take-over. Depending on the number of helpers a breeding pair had in the previous season, $1_{\sigma}$ ranges from 0.59 to $0.64,1_{Q}$ from 0.45 to 0.86 (Table 3 in REYER, 1984). For primary helpers, $1_{\mathrm{H}}$ is 0.54 and $\mathrm{q}_{\mathrm{H}}$ is 0 ; for secondary helpers $l_{\mathrm{H}}$ is 0.74 and $\mathrm{q}_{\mathrm{H}}$ is 0.38 (columns $1,2,6$ and 7 in Tables $3 \mathrm{a}, \mathrm{b}$ ). Consequently, the male's probability ( $\mathrm{p}$ ) of being displaced is 0 in the case of primary helpers and 0.07 to 0.15 in the case of secondary helpers.

These figures on loss in future fitness can only be considered as very rough estimates. They do show that male breeders run a higher risk by accepting secondary helpers than by accepting primary ones, but they are not reliable enough to tell precisely how much higher the risk is. First, the take-over rate is based on small sample sizes. Second, I do not know whether the previous mates actually had been dislodged by their former secondary helpers, or whether the pairs had separated voluntarily. Only one of the three "dislodged" males was without a new female. However, because of the fights and the concomitant risk of injuries (see above), even a breeder that does not lose his female, will incur high costs in defending her against a secondary helper. 


\section{Discussion}

In this section I briefly summarize the six major results from the foregoing analysis of behavioral interactions and food contributions and relate them to the costs and benefits of giving and receiving help.

Costs and benefits of receiving help.

Result 1: During and after the breeding season, male breeders attack and fight potential secondary helpers more often than primary helpers (Table 1, rows 2 and 4, p. 287).

Because of the high male surplus (p. 279) and because helping is an inferior alternative to breeding (REYER, 1984), potential helpers are also potential rivals for male breeders. The above result suggests that secondary helpers impose higher costs and/or lower benefits on the breeding males' fitness than do primary helpers. This indeed is true.

A breeding male has a higher probability of losing his female to an accepted secondary helper $(0.07 \leq p \leq 0.15)$ than to an accepted primary helper ( $p=0$; see $p$. 289). For a primary helper taking over the female may not pay because she is usually his mother and incestuous matings may lead to inbreeding depressions (GreEnwood $e t$ al., 1978). In addition to these costs, a primary helper, whose both parents survive and thus can produce full sibs $(\mathrm{r}=0.5)$, would derive lower benefits from such a takeover than a secondary helper who is only distantly related to the nestlings ( $\mathrm{r} \leq 0.05$; REYER, 1984) unless he successfully copulates himself. A primary helper would improve his coefficient of relatedness to the young only by $0.25(=0.75-0.50)$, whereas a secondary helper would improve it by $0.45(=0.50-0.05)$.

The same reasoning can explain why during nest-digging and copulatory phases male breeders are more tolerant to primary than to potential secondary helpers (Table 1): the probabilities of kleptogamy are likely to differ between the two helper types. On a proximate level, these differential probabilities are reflected by differences in blood plasma levels of testosterone. While titers of potential secondary helpers were found to be as high as those of mated males, those of primary helpers were significantly lower. As low titers were paralleled by small gonad sizes and no sperm production, primary helpers, in contrast to mated males and potential secondary helpers, may not be able to fertilize eggs (REYer et al., 1986).

In addition, even if there were equal chances of kleptogamy from the two helper types and equal losses in present direct fitness to them, a male 
breeder would lose more indirect fitness to a secondary than to a primary helper. This is because secondary helpers are less related to the breeders than primary helpers are $(r>0.05$ vs $r=0.32$; Reyer, 1984). Finally, with respect to feeding nestlings and guarding nests against predators, secondary helpers contribute significantly less to raising young than do primary helpers (Fig. 2 in ReYer, 1984).

Result 2: Primary helpers treat potential secondary helpers in the same way as male breeders do (Table 1, rows 4, 6, 7 and 9).

Primary helpers are closely related to the young they raise $(r=0.32$, REYER, 1984). Therefore, the reasons for their attack and tolerance patterns are similar to those for the male breeder patterns: Assistance from secondary helpers, which improves the survival of the nestlings, will improve the primary helpers' present indirect fitness, whereas kleptogamy will decrease it through reducing the average relatedness. Similarly, female take-overs by secondary helpers, which reduce their fathers' probability of future reproduction, will likewise reduce the primary helpers future indirect fitness. Although similar, the cost/benefit ratios from having secondary helpers are unlikely to be the same for male breeders and primary helpers, mainly because of differences in relatedness to the young. Consequently, subtle differences in their treatment of secondary helpers might be predicted. The present sample size is too small to detect such differences.

Result 3: Female breeders tolerate extra-group males (= potential secondary helpers) more readily than do male breeders and primary helpers (Table 1, rows $4-9)$.

The reaction of males and females toward the approach of extra-group males should depend on the present cost/benefit ratio of promiscuous matings in the two sexes (Gladstone, 1979; Emlen, 1982b; Stacey, 1982; Emlen \& Vehrencamp, 1983) as well as on the males' future costs resulting from mate take-over. In some social species, even females seem to avoid contact with extra-pair males and-when forcefully mated-will adopt postures that make insemination unlikely (e.g. EMLEN \& WREgE, 1986). Thus, both sexes seem to lose from tolerating other males. In others species, female promiscuity is a regular phenomenon although reproductive monopolization by a single male would appear to be possible, at least in some of these cases (see EMLEN, 1982b; Stacey, 1982, and literature therein). Here, both sexes seem to gain. Between these two extremes are those species in which birds of either sex may accept more 
than one bird of the opposite sex, but are prevented from doing so by their mates who closely guard them, especially during the time of egglaying (Hoogland \& Sherman, 1976; Birkhead, 1979; Power \& Doner, 1980; Mumme et al., 1983; Sonnenschein \& Reyer, 1983; Emlen \& WREGE, 1986). As to tolerance of potential secondary helpers, the pied kingfisher belongs to the last group. This suggests that secondary helpers are potential rivals for group-males but not for females. The threat to group males (kleptogamy and loss of mates) has already been discussed under Results 1 and 2. Females are unaffected by these costs and can even benefit from such male-male competition in various ways:

1. Receiving fish from many males, as part of their courtship displays, can guarantee a better energy supply for egg formation. This is particularly important in fish-eating species like the pied kingfisher, in which energetic costs of foraging seem to be high and females rarely seek food for themselves shortly before and during egg-laying (cf. list of courtship feeding birds in Drent \& DaAN, 1980; see also Nisbet, 1977).

2. After hatching, the survival rate of the young increases with the number of helpers/pair (REYER, 1980, 1984).

3. The more helpers a female has, the more she can reduce her own food contributions to the young, and the higher will be her probability of survival (Fig. 2b and Table 3 in Reyer, 1984).

Possible costs of tolerating potential secondary helpers may arise from a female's increased chance of being deserted by her mate when he finds her with other males (Gladstone, 1979). As a female is unable to raise her brood alone, such desertion would mean a loss of her previous investment. However, in a species with a high surplus of males and consequently low chances of finding another female, the risk of desertion must be very low. Moreover, having his female supplied with fish from other males will even benefit a mated male, provided he can prevent these males from copulating with her. This is precisely what male breeders (and their primary helpers) do when they intercept potential secondary helpers before and during egg-laying and take their fish to the female (p. 282).

Where cooperation of other males raises the reproductive success of breeders, mated males will even benefit from tolerating promiscuous matings of their females, provided the fitness loss from shared paternity is more than compensated for by the benefits from getting helpers which would not have assisted, if prevented from fertilizing eggs (see models of Emlen, 1982b; Stacey, 1982; Brown, 1985). In pied kingfishers, helpers do significantly improve the reproductive success but they assist breeders 
even without having copulated. This is because helping markedly improves the secondary helpers' own future reproductive chances, making it a far more profitable alternative than non-helping (Table 7 in REYER, 1984). In this situation, mated males can monopolize reproduction and avoid the costs of promiscuous matings without losing the benefits of assisting secondary helpers (Vehrencamp, 1979, 1983; EmLen, 1982b; EmLen \& Vehrencamp, 1983).

As to survival of young, the group-males' benefits resemble those of females (point 2 above). Female benefits 1 and 3, however, are less important for males, who have no energy demand for producing eggs. Also, with regard to feeding rates and survival, males profit much less from increasing numbers of secondary helpers than do females (Fig. $2 \mathrm{~b}$ and Table 3 in REYER, 1984). Thus, for males the presence of secondary helpers not only involves higher costst, but also lower benefits than is true for females.

Result 4: By transferring fish to group-members secondary helpers reduce the probability of being attacked (Table 1, rows 4-9).

The "appeasing" effect of food transfer, which has long been known to ethologists, is best explained by considering a helper's feeding as the "payment" for being tolerated within a group (Gaston, 1978). By offering food, the potential secondary helper can lower the other group members' foraging effort and/or increase their reproductive output to such an extent that their fitness gain from accepting the helper exceeds the gain from rejecting him (see "breeder tolerance line" and "sociality threshold" in models of EMLEN, 1982b and BROwn, 1985).

As the cost/benefit ratio from having secondary helpers varies with sex and time of the breeding season (see Discussion of Results 1-3), it is not surprising that the reaction to the secondary helpers' payment varies as well. Female breeders, who benefit during the time of egg formation, accept potential secondary helpers prior to laying, especially when they are offered a fish (Table 1, row 5). For group-males, however, for whom the cost/benefit ratio is high during the early stages of the breeding season, receiving a fish is not sufficient payment for tolerating the secondary helper (Table 1, rows 4 and 6). This changes after hatching (Table 1, rows 7 and 9), when there is no longer a risk of kleptogamy, and when helpers can significantly improve survival of the young.

As the second and third helper improve the nestlings' survival to a lesser extent than the first helper does (REYER, 1980, 1984), the average benefit from each helper is lower in a big group than in a small one. In 
such a situation breeders can "demand" a higher payment for the same tolerance (see models by Vehrencamp, 1978, 1983; EmLen, 1982b; EmLen \& Vehrencamp, 1983; Brown, 1985). This offers one explanation why in groups with two or three secondary helpers each helper provided the nestlings with more food than in groups with only one helper. (Another possible explanation will be discussed under Result 6.)

Similar reasoning may explain why in many cooperative breeders older helpers bring more food to the nestlings than younger helpers do (e.g. Brown, 1972; Ligon \& Ligon, 1978; Stallcup \& Woolfenden, 1978; Rowley, 1981). Even when old and young helpers benefit equally from remaining in a safe territory, older birds may have to pay more for being tolerated, because increasing age raises the probability that a helper will live with his stepparent(s) rather than with his parent(s) (cf. TABORSKY, 1985). Replacement of a mother by a stepmother will eliminate the risk of incest and therefore may lead to an increase in the helper's copulation attempts; replacement of a father by a stepfather will increase the male breeder's loss in inclusive fitness if such copulation attempts are successful. In addition, an older helper's greater experience probably makes him a more serious competitor. This is an alternative, although not mutually exclusive explanation to the usual interpretation which states that the higher contribution of older helpers reflects their higher chances of becoming independent breeders (WoOLFEndEN \& FitzPatrick, 1977, 1978; Ligon \& Ligon, 1978, 1983; Stallcup \& WoolFENDEN, 1978).

Where benefits from helpers fall very low, e.g. because parents have only a few young to raise or because food is easily available, the helpers' payment may no longer be accepted at all. Under normal conditions, this happens at Lake Naivasha, where food supply is better than at L. Victoria and parents have a lower feeding effort and higher reproductive success (REYer, 1980). Experimental increase of clutch size and concomittant increase in parental energy expenditure can make L. Naivasha breeders switch from rejecting to tolerating helpers. Conversely, at L. Victoria, experimental decrease of clutch size and feeding effort can change the breeders' behavior from tolerance to rejection (REYER \& WeSTERTERP, 1985). The only other experimental evidence for helping as a payment in relation to need comes from a study on Lamprologus brichardi, a cooperatively breeding cichlid fish in wich helpers aid in territory defence (TABORSKY \& LimBerger, 1981; TABORSKY, 1984). By adding competitors, parents could be induced to re-accept helpers which they formerly had expelled from their territory (TABORSKY, 1985). 
Costs and benefits of helping.

Result 5: After the nestlings hatch, primary helpers invest more in the young (usually sibs) than in females, whereas secondary helpers invest more in females (= potential mates) than in the unrelated young (Fig. 1, Table 2).

This result supports the previous finding that increased production of close kin is the most important component of a primary helper's inclusive fitness, whereas take-over of females, improving chances of independent reproduction, is the main benefit for secondary helpers (see REYER, 1984 and Discussion of Result 1 for details and for literature).

Result 6: In groups with two or more secondary helpers, each helper tends to provide the nestlings with more food than in groups with only one secondary helper (Fig. 2).

Although none of the differences in Fig, 2 are very convincing in themselves, partly because of a conservative test (p. 286), results from number, size and type of fish supplement each other. They suggest that the secondary helpers' relative feeding effort increases with group size, although a decrease is to be expected (cf. e.g. Brown et al., 1978). One possible explanation for the surprising increase in feeding has already been mentioned in the discussion of result 3: the average benefit to breeders from an individual helper is lower in bigger than in smaller groups, and this necessitates a higher payment for being tolerated.

Another, not mutually exclusive, explanation considers a secondary helper's feeding as a signal to a female who could become his future mate. In some cooperative breeders, helpers intensively try to feed adults and/or young directly, sometimes after stealing prey from other group members (Ligon \& Ligon, 1978, 1983; Stallcup \& Woolfenden, 1978). Sometimes food is even offered to young outside the cooperative unit (Balda \& Balda, 1978; Dow, 1977; Brown \& Brown, 1980; Ligon \& Ligon, 1983). In some mammals, dominant non-breeders may prevent more subordinate ones from helping (Macdonald \& Moenlman, 1982). These and other observations strongly suggest that feeding can serve to establish a bond between donor and recipient, and that helpers compete over these bonds because they benefit from them as to their own future reproduction,e.g. by recruiting a mate or a helper (BROWN, 1978; EMLEN, 1978, 1984; Ligon \& LigON, 1978; Brown \& Brown, 1980).

However, in species in which males make a substantial contribution to parental care, a female should not mate with any male that feeds her. She should rather choose her mate among other criteria on the basis of the amount of food brought to her by the male, using this as a predictor of his 
later parental performance (Trivers, 1972; Halliday, 1978, 1983; Searcy, 1979). Support for this hypothesis is usually taken from courtship feeding (e.g. Nisbet, 1977; TAsker \& Mills, 1981), but I don't know of any study unambiguously proving that (a) good courtship feeders are more likely to be chosen by females than poor feeders, and (b) good courtship feeders are good parents. For pied kingfishers I do not have these data either. However, there is some indirect evidence for the role of feeding in mate choice.

(a) A secondary helper's attempt to associate with a female is more successful when fish are brought than when they are not (Table 1, row 5).

(b) Secondary helpers consistently feed females large cichlids (cp. narrow interquartile range in hatched bar of Fig. 1a). This makes the transferred food conspicuous and stereotyped. Both, conspicuousness and stereotypy are typical features of signals and increase the reliability of signal detection (WILEY, 1983).

(c) Secondary helpers, arriving with a fish in the colony, sometimes seem to delay feeding of the young until the female is present and can see them going into the nest (REYER, unpubl. data).

If, as indicated by these results, feeding is important in mate choice, secondary helpers should feed more to females and young where competition for females, and consequently the necessity to demonstrate their mate qualities, is higher. This is exactly what they did in groups with two or three helpers as opposed to groups with only one helper. Yet, even in the bigger groups, each helper seemed to take less food to the young than the male breeders did (Fig. 2). Why don't better feeders invade the system and outcompete male breeders and poorly feeding secondary helpers?

The success of a helper feeding many big fish over a helper feeding few small fish would depend (a) on the female's discriminating ability, and (b) on the relative fitness gained by males that contribute differentially.

(a) Discriminating abilities of females.

When seeing helpers near the nest, females can probably discriminate between males holding a big fish and males holding a small one, although this discrimination may not be perfect. Females should also be able to tell the difference between a slender Engraulicypris and a bulky cichlid.

A single fish, however, gives no reliable record of the total feeding contribution. Parents and primary helpers occasionally feed small fish as well (cf. wide interquartile range in black bar of Fig. 1a). Moverover, not all feedings occur in the presence of the female. Therefore, the frequency of 
feeding may be less easy to monitor by females than size and type of fish, and consequently feeding frequency offers the males more possibilities to deceive. It is interesting to note that differences between the feeding contributions of secondary helpers from big and small groups seem to be more pronounced in fish size and E/C-ratio than in number of fish (Fig. $2 b-d)$.

Females could counteract such possible deceit by paying less attention to numbers than to size and type, i.e. by devaluating the fakeable signal (cf. WiLEY, 1983). Alternatively, they could try to get a reliable record of the males' feeding frequencies by remaining near the nest and closely approaching birds returning with fish. Such behavior, however, would conflict with a female's own fishing activity. To what extent the resulting improvement in the helper's contribution and the inevitable decrease in her own contribution would affect a female's fitness remains speculation. The fact, however, that with increasing food demands of the young the females increasingly fish themselves rather than wait for helpers suggests that too fine a distinction between good and poor feeders may not pay.

(b) Relative fitness gain of good and poor feeders.

Even if the females' discrimination would favour good over poor feeders, the relative fitness gain of males pursuing these different tactics would not. In the following calculation $l_{\mathrm{H}}$ is the probability for a poorly feeding secondary helper to survive into the next year, $\mathrm{l}_{\mathrm{H}}{ }^{\prime}$ that for a secondary helper feeding as much as parents and primary helpers do. Further, $\mathrm{m}_{\mathrm{H}}$ and $m_{H^{\prime}}$ are the corresponding chances of the surviving helpers to recruit mates, either from the helped females or from others. Poor feeders would be replaced by better feeders if $1_{\mathrm{H}}{ }^{\prime} \cdot m_{\mathrm{H}}{ }^{\prime}>\mathrm{l}_{\mathrm{H}} \cdot \mathrm{m}_{\mathrm{H}}$. Under the present system $l_{\mathrm{H}}=0.74$ and $\mathrm{m}_{\mathrm{H}}=0.91$ (Table 3 , columns 5-7). If mate choice would depend on feeding contributions alone, and thus the best among the surviving feeders would get a mating chance of $m_{H^{\prime}}{ }^{\prime}=1$, the above inequality would reduce to $l_{\mathrm{H}}{ }^{\prime}>0.67$. In other words, the better feeder must have a more than $67 \%$ chance of survival to succeed over the poor feeder. This is an unrealistic figure. Bringing more and bigger fish as well as a lower E/C-ratio to nestlings would mean a considerable increase in time and energy expenditure (REYER, 1984; REYER \& WESTERTERP, 1985). This is not only because the helpers could swallow fewer big, nutritious fish themselves; it is also because cichlids are more difficult to catch (Fig. 3a in Reyer, 1984), and because big fish require more handling time (Douthwaite, 1971). As there is a significant 
negative correlation between energy expenditure and survival rate, feeding as much as parents and primary helpers would decrease the secondary helper's probability of survival $\left(l_{\mathrm{H}}{ }^{\prime}\right)$ to average values between 0.59 and 0.64 (see p. 289 and Table 3 in Reyer, 1984). This is less than the required limit of 0.67 . The discrepancy would be even bigger with mating chances of $m_{H^{\prime}}<1$ which would occur if, for whatever reason, the female preferred her old mate, whether or not the helper feeds as much or more.

Part of that discrepancy could be compensated for through kin benefits from the nestlings' increased survival and/or through increased direct benefits when these same young act as primary helpers next year if the former secondary helper gets to breed. Both benefits, however, are insignificant for secondary helpers, kin benefits mainly because of the helpers' low relatedness to the nestlings ( $r \leq 0.05$ ), direct benefits mainly because of the low probability that the raised young will assist the secondary helper next year $(\mathrm{p}=0.095, \mathrm{n}=21)$. From the figures given in this paper and from previously published data on reproductive success in relation to number of helpers per pair (Table 6 in REYER, 1984), it can be calculated that, under the present system, a secondary helper will reach an average inclusive fitness value of 0.97 genetic equivalents after two years (see formulas 2-3b in REYER, 1984), whereas a helper, feeding as much as parents, would only yield values between 0.82 and 0.95 . A helper, trying to feed more than parents, would even gain less. Thus, a higher feeding contribution and the concomitant increase in mortality would lead to a loss in fitness rather than to a gain.

In conclusion, all recorded interactions and food contributions of pied kingfisher breeders and helpers strongly support predictions from the cost/benefit ratios of giving and receiving help. In other cooperative breeders some costs and benefits for breeders and helpers may differ from those in pied kingfishers, but once they have been identified, it should be possible to detect behavioral signs of the breeder-helper-conflict in any species. As shown in this paper, these signs are not limited to overt aggression. They can find more subtle expressions (e.g. in feeding contributions to different group members) which are only discovered when several behavior patterns and interactions of breeders and helpers are quantified. Conversely, such quantifications, which are surprisingly rare in studies of cooperative breeding, can be a helpful tool for shedding light on the costs and benefits of giving and receiving help. This is especially true when the costs and benefits are confounded by numerous interacting demographic and ecological parameters (cf. Introduction). 


\section{Summary}

In most social species there is not only cooperation but also conflict between group members. Although various theoretical models have specified the conditions for, and the extent and direction of conflict and cooperation, there are few empirical data to test their predictions. This paper reports such a test for the pied kingfisher (Ceryle rudis), a cooperatively breeding bird species with two types of male helpers: primary (= related) and secondary ( = unrelated).

In a breeding colony at Lake Victoria (Kenya), the birds were studied with regard to: (a) aggressive and non-aggressive interactions between breeders and helpers before and after chicks hatched; (b) frequency and effect of prey transfer from helpers to breeders; and (c) sizes and types of prey brought to females and nestlings. The six major results of the study and their explanations are as follows:

Result 1. Male breeders attack secondary male helpers more often than primary helpers (Table 1). Explanation: Because of a high male surplus, all helpers are also potential rivals, competing with male breeders for sexual access to the scarce females. Secondary helpers, however, impose higher costs and lower benefits on the male breeders' fitness than do primary helpers. This is because they provide less help, seem to be more capable of fertilizing eggs in the year of help, are more likely to displace breeders in subsequent years, and are more distantly related to breeders than are primary helpers.

Result 2. Primary helpers treat secondary helpers in the same way as male breeders do (Table 1). Explanation: Primary helpers are closely related to the young they raise. Therefore, any competition from secondary helpers that affects the breeder will decrease the primary helpers inclusive fitness.

Result 3. Female breeders tolerate secondary helpers more readily than do male breeders and primary helpers (Table 1). Explanation: Females do not incur the costs of male-male competition; indeed they even benefit from it, because (a) with additional males (= secondary helpers) they get a better food supply during egg formation than without them, and (b) secondary helpers lower the females' food contributions to nestlings more than those of male breeders and primary helpers.

Result 4. By offering fish, secondary helpers reduce the probability that they will be attacked by the breeding pair and any primary helpers (Table 1). Explanation: The helpers' food transfer is interpreted as a "payment" for being accepted as a group member. Receiving fish improves the breeders' and primary helpers' energy-budgets and their chances of fledging young and thus reduces the cost/benefit ratio of tolerating helpers. For females this holds already during egg formation, for males only after hatching, when the risk of kleptogamy is low, and when helpers can improve survival of the young.

Result 5. After the young have hatched, primary helpers carry more food to nestlings (= usually their sibs) than to females, whereas secondary helpers carry more to females than to unrelated nestlings (Table 2 and Fig. 1). Explanation: Primary helpers increase their inclusive fitness mainly through raising close kin, secondary helpers mainly through improving their chances of finding a mate and reproducing themselves.

Result 6 . In groups with two or three secondary helpers, each helper tends to provide the nestlings with more food than in groups with only one helper (Fig. 2). Explanation: Groups with two or three secondary helpers differ from groups with only one helper (a) in the breeders' average gain from each helper, and (b) in the extent of male-male competition for females as prospective mates. The helpers' higher food contribution to nestlings in bigger groups is interpreted (a) as a higher payment for being tolerated, and (b) as increased effort to signal their parental qualities to the females.

It is concluded that all behavioral interactions and food contributions closely reflect the costs and benefits of giving and receiving help, which vary with the sex of the breeder, the relatedness between the group members, and the period of the reproductive cycle. 


\section{References}

BAlda, R. P. \& BALdA, J. H. (1978). The care of young piñon jays (Gymnorhinus cyanocephalus) and their integration into the flock. - J. Ornithol. 119, p. 146-171.

Birknead, T. R. (1979). Mate guarding in the magpie Pica pica. - Anim. Behav. 27, p. 866-874.

BRown, J. L. (1972). Communal feeding of nestlings in Mexican jay (Aphelocoma ultramariana): Interflock comparison. - Anim. Behav. 20, p. 395-403.

- - (1974). Alternate routes to sociality in jays - with a theory for the evolution of altruism and communal breeding. - Am. Zool. 14, p. 63-80.

- (1978). Avian communal breeding systems. - Ann. Rev. Ecol. Syst. 9, p. 123-155.

- - (1982). Optimal group size in territorial animals. - J. theor. Biol. 95, p. 793-810.

- - (1985). The evolution of helping - An ontogenetic and comparative perspective. In: The comparative development of adaptive skills: Evolutionary implications (E. Gollin, ed.), p. 137-171. Erbaum Associates, Inc. Publ., Hilldale, N.Y.

- - \& Brown, E. R. (1980). Reciprocal aid-giving in a communal bird. - Z. Tierpsychol. 53, p. 313-324.

- -, Dow, D. D., Brown, E. R. \& Brown, S. D. (1978). Effects of helpers on feeding nestlings in the grey-crowned babbler (Pomatostomus temporalis). - Behav. Ecol. Sociobiol. 4, p. 43-59.

Douthwaite, R. J. (1971). The treatment of fish by the pied kingfisher Ceryle rudis. Ibis 113 , p. 526-529.

- - (1973). Pied kingfisher Ceryle rudis populations. - Ostrich 44, p. 89-94.

Dow, D. D. (1977). Reproductive behavior of the noisy miner, a communally breeding honeyeater. - The Living Bird 16, p. 163-185.

- - (1979). Agonistic and spacing behaviour of the noisy miner Manorina melanocephala, a communally breeding honeyeater. - Ibis 121, p. 423-436.

Drent, R. H. \& DaAN, S. (1980). The prudent parent: Energetic adjustment in avian breeding. - Ardea 68, p. 225-252.

Dunn, E. K. (1985). Ceryle rudis, pied kingfisher - Social pattern and behaviour. In: Handbook of the birds of Europe, the Middle East and North Africa (S. CRAMP, ed.), p. 726-728. Oxford University Press, Oxford.

EMLEN, S. T. (1978). The evolution of cooperative breeding in birds. - In: Behavioural ecology: An evolutionary approach (J. R. Krebs \& N. B. Davies, eds), p. 245-281. Blackwell, Oxford.

- - (1982a). The evolution of helping. I. An ecological constraints model. - Am. Nat. 119 , p. 29-39.

- - (1982b). The evolution of helping. II. The role of behavioral conflict. - Am. Nat. 119, p. $40-53$.

- - (1984). Cooperative breeding in birds and mammals. - In: Behavioural ecology. An evolutionary approach, 2nd edition (J. R. Krebs \& N. B. Davies, eds), p. 305-339. Blackwell, Oxford.

- - \& Vehrencamp, S. L. (1983). Cooperative breeding strategies among birds. - In: Perspectives in ornithology (A. H. Brush \& G. A. Clark, Jr., eds), p. 93-120. Cambridge University Press, Cambridge.

- — \& WREGE, P. H. (1986). Forced copulations and intra-specific parasitism. Two costs of social living in the white-fronted bee-eater. $-\mathrm{Z}$. Tierpsychol. (in press).

Gaston, A. J. (1978). The evolution of group territorial behavior and cooperative breeding. - Am. Nat. 112, p. 1091-1100.

Greenwoon, P. J., Harvey, P. H. \& Perrins, C. M. (1978). Inbreeding and dispersal in the great tit. - Nature 271, p. 52-54.

Gladstone, D. E. (1979). Promiscuity in monogamous colonial birds. - Am. Nat. 114, p. $545-557$. 
Halliday, T. R. (1978). Sexual selection and mate choice. - In: Behavioural ecology. An evolutionary approach (J. R. KREBS \& N. B. Davies, eds), p. 180-213. Blackwell, Oxford.

- - (1983). The study of mate choice. - In: Mate choice (P. P. G. Bateson, ed.), p. 3-32. Cambridge University Press, Cambridge.

HeRT, E. (1985). Individual recognition of helpers by breeders in Lamprologus brichardi (Cichlidae). - Z. Tierpsychol. 68, p. 313-325.

Hoogland, J. L. \& Sherman, P. W. (1976). Advantages and disadvantages of bank swallow (Riparia riparia) coloniality. - Ecol. Monogr. 46, p. 33-58.

Joste, N. E., Koenig, W. D., Mumme, R. L. \& Pitelka, F. A. (1982). Intragroup dynamics of a cooperative breeder. An analysis of reproductive roles in the acorn woodpecker, - Behav. Ecol. Sociobiol. 11, p. 195-201.

Koenig, W. D. \& Pitelka, F. A. (1981). Ecological factors and kin selection in the evolution of cooperative breeding in birds. - In: Natural selection and social behavior. Recent research and new theory (R. D. Alexander \& D. W. Tinkle, eds), p. 261-280. Ciron Press, New York.

Ligon, J. L. \& Ligon, S. H. (1978). Communal breeding in the green woodhoopoe as a case for reciprocity. - Nature 176, p. 496-498.

- - \& - - (1983). Reciprocity in the green woodhoopoe (Phoeniculus purpureus). Anim. Behav. 31, p. 480-489.

Macdonald, D. W. \& Moehlman, P. D. (1982). Cooperation, altruism, and restraint in the reproduction of carnivores. - In: Perspectives in ethology, Vol. 5 ( $\mathrm{P}$. Klopfer \& P. Bateson, eds), p. 433-466. Plenum Press, New York.

Mumme, R. L., Koenig, W. D. \& Pitelka, F. A. (1983). Mate-guarding in the acorn woodpecker: within-group competition in a cooperative breeder. - Anim. Behav. 31, p. $1094-1106$.

Nisbet, I. C. T. (1977). Courtship feeding and clutch size in common terns, Sterna hirundo. - In: Evolutionary ecology (B. Stonehouse \& C. M. Perrins, eds), p. 101-109. Macmillan, London.

Power, H. W. Doner, C. G. P. (1980). Experiments on cuckoldry in the mountain bluebird. - Am. Nat. 116, p. 689-704.

Reyer, H.-U. (1980). Flexible helper structure as an ecological adaptation in the pied kingfisher, Ceryle rudis. - Behav. Ecol. Sociobiol. 6, p. 219-227.

- (1984). Investment and relatedness. A cost/benefit analysis of breeding and helping in the pied kingfisher (Ceryle rudis). - Anim. Behav. 32, p. 1163-1178.

- - \& Dunn, E. K. (1985). Ceryle rudis, pied kingfisher-voice. - In: Handbook of the birds of Europe, the Middle East and North Africa (S. Cramp, ed.), p. 728-729. Oxford University Press, Oxford.

- - Dittami, J. \& Hall, M. (1986). Avian helpers at the nest. Are they psychologically castrated? - Z. Tierpsychol. (in press).

- - \& Westerterp, K. (1985). Parental energy expenditure. A proximate cause for helper recruitment in the pied kingfisher. - Behav. Ecol. Sociobol. 17, p. 363-369.

Rowley, I. (1981). The communal life of the splendid wren, Malurus splendens. $-\mathrm{Z}$. Tierpsychol. 55, p. 228-267.

SEArCy, W. A. (1979). Female choice of mates. A general model for birds and its application to red-winged blackbirds (Agelaius phoeniceus). - Am. Nat. 114, p. 77-100.

Sokat, R. R. \& Rohlf, F. J. (1969). Biometry. - Freeman, San Francisco.

Sonnenschein, E. \& Reyer, H.-U. (1983). Mate-guarding and other functions of antiphonal duets in the slate-coloured boubou (Laniarius funebris). - Z. Tierpsychol. 63, p. $112-140$.

Stacey, P. B. (1982). Female promiscuity and male reproductive success in social birds and mammals. - Am. Nat. 120, p. 51-64.

Stallcup, J. A. \& Woolfenden, G. E. (1978). Family status and feeding contributions to breeding by Florida scrub jays. - Anim. Behav. 26, p. 1144-1156. 
Sugg, M.St-J. (1974). Mensural and moult data from a breeding colony of pied kingfishers. - Ostrich 45, p. 227-234.

TавоRSкy, M. (1984). Broodcare helpers in the cichlid fish Lamprologus brichardi. Their costs and benefits. - Anim. Behav. 32, p. 1236-1252.

- (1985). Breeder-helper conflict in a cichlid fish with broodcare helpers. An experimental analysis. - Behaviour 95, p. 45-75.

- - \& Limberger, D. (1981). Helpers in fish. - Behav. Ecol. Sociobiol. 8, p. 143-145.

Tasker, C. R. \& Mills, J. A. (1981). A functional analysis of courtship-feeding in the red-billed gull, Larus novahollandiae scopulinus. - Behaviour 77, p. 222-241.

Trivers, R. L. (1972). Parental investment and sexual selection. - In: Sexual selection and the descent of man (B. CAmprell, ed.), p. 139-179. Aldine, Chicago.

Vehrencamp, S. L. (1979). The roles of individual, kin, and group selection in the evolution of sociality. - In: Handbook of behavioral neurobiology, Vol. 3 ( $\mathrm{P}$. Marler \& J. G. Vandenbergh, eds), p. 351-394. Plenum Press, New York.

- (1983). A model for the evolution of despotic versus egalitarian societies. - Anim. Behav. 31, p. 667-682.

WILEY, H. (1983). The evolution of communication: Information and manipulation. In: Communication. Animal behaviour, Vol. 2 (T. R. Halliday \& P. J. B. Slater, eds), p. 156-189. Blackwell, Oxford.

Woolfenden, G. E. \& Fitzpatrick, J. W. (1977). Dominance in the Florida scrub jay. - Condor 79, p. 1-12

$--\&--(1978)$. The inheritance of territory in group-breeding birds. - BioScience 28, p. 104-108.

\section{Zusammenfassung}

Bei den meisten sozial lebenden Tieren gibt es nicht nur Zusammenarbeit sondern auch Konflikt zwischen den Gruppenmitgliedern. Die Bedingungen für, sowie das Ausmaß und die Richtung von Konflikt und Zusammenarbeit sind in verschiedenen theoretischen Modellen dargelegt, aber selten empirisch getestet worden. Diese Arbeit beschreibt einen solchen Test für den Graufischer (Ceryle rudis), eine Vogelart mit kooperativer Jungenaufzucht und zwei Typen von männlichen Helfern: primären (= verwandten) und sekundären (= nicht verwandten).

In einer Brutkolonie am Viktoriasee in Kenya wurden folgende Parameter gemessen: (a) aggressive und nicht-aggressive Interaktionen zwischen Brutvögeln und Helfern, vor und nach dem Schlüpfen der Jungen; (b) Häufigkeit und Auswirkungen von Fischübergabe zwischen Helfern und Brutvögeln; und (c) Größe und Art der Fische, mit denen Weibchen und Nestlinge gefüttert werden. Die sechs wesentlichen Ergebnisse der Untersuchung und ihre Erklärungen sind folgende:

Ergebnis 1. Brutmännchen greifen sekundäre Helfer häufiger an als primäre Helfer (Tabelle 1). Erklärung: Wegen eines hohen Männchen-Überschusses sind alle Helfer auch potentielle Rivalen, die mit den Brutmännchen um die Weibchen konkurrieren. Sekundäre Helfer bedeuten jedoch ein größeres Risiko und einen geringeren Gewinn für die Fitness der Brutmännchen als primäre Helfer. Das liegt daran, daß sekundäre Helfer die Jungen weniger füttern als primare Helfer, mit den Brutvögeln weniger verwandt sind und eher in der Lage sind mit den Weibchen zu kopulieren oder sie sogar in folgenden Jahren ganz zu übernehmen.

Ergebnis 2. Primäre Helfer behandeln sekundäre Helfer in der gleichen Weise wie Brutmännchen das tun (Tabelle 1). Erklärung: Primäre Helfer sind mit den Brutmännchen und den Jungen, die sie aufziehen, eng verwandt. Jede Konkurrenz durch sekundäre Helfer, welche die Fitness der Brutmännchen verringert, beeinträchtigt daher auch die Gesamtfitness der primären Helfer. 